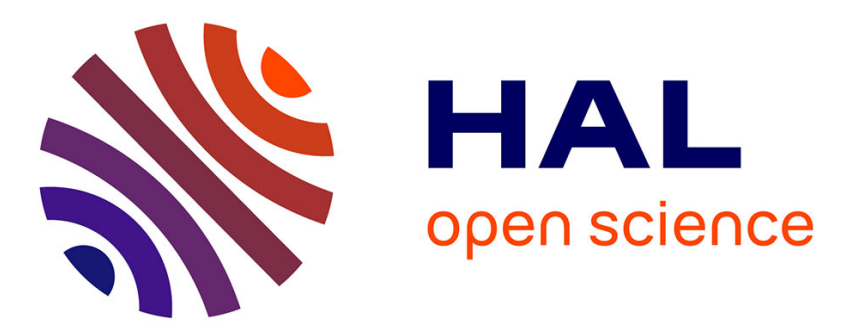

\title{
Two Propagation Scenarios of Isolated Breakdown Lightning Processes in Failed Negative Cloud-to-Ground Flashes
}

Ivana Kolmašová, Ondřej Santolík, Eric Defer, Petr Kašpar, Andrea Kolínská, Stéphane Pedeboy, Sylvain Coquillat

\section{To cite this version:}

Ivana Kolmašová, Ondřej Santolík, Eric Defer, Petr Kašpar, Andrea Kolínská, et al.. Two Propagation Scenarios of Isolated Breakdown Lightning Processes in Failed Negative Cloud-to-Ground Flashes. Geophysical Research Letters, 2020, 47 (23), 10.1029/2020GL090593 . hal-03042155

\section{HAL Id: hal-03042155 https://hal.science/hal-03042155}

Submitted on 8 Dec 2020

HAL is a multi-disciplinary open access archive for the deposit and dissemination of scientific research documents, whether they are published or not. The documents may come from teaching and research institutions in France or abroad, or from public or private research centers.
L'archive ouverte pluridisciplinaire HAL, est destinée au dépôt et à la diffusion de documents scientifiques de niveau recherche, publiés ou non, émanant des établissements d'enseignement et de recherche français ou étrangers, des laboratoires publics ou privés. 
1 Two propagation scenarios of isolated breakdown lightning processes in failed negative cloud-to-ground flashes

3

$4 \quad$ Ivana Kolmašová

5 Department of Space Physics, Institute of Atmospheric Physics of the Czech Academy of

6 Sciences, Prague, Czechia

7 Faculty of Mathematics and Physics, Charles University, Prague, Czechia

8

9 Ondřej Santolík

10 Department of Space Physics, Institute of Atmospheric Physics of the Czech Academy of 11 Sciences, Prague, Czechia

12 Faculty of Mathematics and Physics, Charles University, Prague, Czechia

14 Eric Defer

15 Laboratoire d'Aérologie, Université de Toulouse, CNRS, OMP, UPS, Toulouse, France 16

17 Petr Kašpar

Department of Space Physics, Institute of Atmospheric Physics of the Czech Academy of Sciences, Prague, Czechia

21 Andrea Kolínská

22 Department of Space Physics, Institute of Atmospheric Physics of the Czech Academy of 23 Sciences, Prague, Czechia

24 Faculty of Nuclear Sciences and Physical Engineering, Czech Technical University, Prague,

25 Czechia

27 Stéphane Pedeboy

28 Météorage, Pau, France

29

30 Sylvain Coquillat

31 Laboratoire d'Aérologie, Université de Toulouse, CNRS, OMP, UPS, Toulouse, France 
34 Corresponding author: I. Kolmašová, Institute of Atmospheric Physics of the Czech Academy of

35 Sciences, Boční II 1401, 14100 Prague 4, Czechia (iko@ufa.cas.cz) 


\section{$37 \quad$ Key points}

- Preliminary breakdown radiowave pulses typical for negative cloud-to-ground flashes are exceptionally observed without return strokes.

- Data show evidence of two possible propagation scenarios: the discharge leader either extends horizontally inside the cloud or fades out.

- The first analysis of a large number of events shows that waveform characteristics of pulse trains are very similar for both scenarios.

Plain language summary

$47 \quad$ Visible lightning return stroke represents a well-known manifestation of atmospheric electricity. However, it is only the last stage of a complex sequence of phenomena that starts inside an electrically charged thundercloud by a preliminary breakdown process, continues by a stepped leader that moves electrical charges into the lightning channel, neutralized eventually by a large return stroke current and followed in most cases by processes leading to subsequent strokes. All these phenomena occurring inside or below the thundercloud involve impulsive electrical currents and hence emit radio waves. Analysis of our observations of isolated breakdown radiowave pulses,

54 which are not followed by a return stroke shows that the underlying processes are similar to a usual 55 preliminary breakdown preceding negative cloud-to ground discharges. Nevertheless, a strong 56 positive charge layer at the bottom of the thundercloud can force the breakdown current pulses to 57 keep flowing inside the cloud or die out, and thus prevents them from evolving into a return stroke 58 that would move the negative charge from the cloud to the ground.

\section{Abstract}


61 Isolated breakdown process (also known as attempted leader or inverted intra-cloud discharge) is

62 a lightning phenomenon characterized by radiowave pulses similar to signatures of preliminary

63 breakdown before negative cloud-to-ground flashes, but in this case no cloud-to-ground return

64 strokes occur. We identified 128 isolated breakdown pulse trains in measurements collected in the

65 Mediterranean by a broadband receiver $(0.005-37 \mathrm{MHz})$ in 2015 and 2018 . By combining these

66 records with concurrent Lightning Mapping Array measurements of very high frequency radiation

$67(60-66 \mathrm{MHz})$ emitted by in-cloud discharges we investigate the development of each discharge.

68 We identify two scenarios: either the discharges continue to propagate almost horizontally for

69 more than $150 \mathrm{~ms}(73 \%)$, or they quickly fade out $(27 \%)$. The geo-localized sources of the

70 observed isolated breakdown pulse trains, together with their waveform characteristics (duration,

71 inter-pulse intervals, regularity, bipolar shapes) show that both scenarios are similar to initiation

72 processes preceding negative cloud-to-ground flashes.

73

74

75

76 Index terms: 3304 Atmospheric electricity

77

3324 Lightning

78

3394 Instruments and techniques

79

80

81 1. Introduction 
Both cloud-to-ground (CG) and intra-cloud (IC) lightning flashes usually start with a preliminary breakdown (PB) process (sometimes referred to as initial breakdown) which is characterized by a presence of trains of bipolar pulses in electromagnetic recordings (Marshall et al., 2014a and references herein). These pulse trains are emitted by in-cloud currents and can be detected hundreds of kilometers from their source (Kolmasova et al., 2016, Kotovsky et al.,

87 2016). Measurements conducted several kilometers from lightning recently showed that the first PB pulse is preceded by an ionizing initiation event followed by an initial electric field change (Marshall et al., 2014b, 2019). The PB stage of negative CG lightning flashes usually converts into a stepped leader followed by the first return stroke (RS) (Rakov \& Uman, 2003 and references herein). and Knundsen (1956) reported for the first time an observation of "pre-discharges lacking the 94 main discharge". Nag and Rakov (2008) described observation of trains of electric field pulses, 95 which were not followed by RS pulses. These isolated trains possessed characteristics of PB sequences preceding negative CG discharges. They named them "first attempted cloud-to-ground

97 leaders". Sharma et al. (2008) introduced a term "isolated breakdown" for PB sequences which did not lead to any subsequent activity and compared properties of isolated breakdown pulse

99 trains with those leading to RSs They found that durations of pulse trains and inter-pulse time 100 intervals were comparable for isolated breakdown and PB pulse trains. Kolmasova et al. (2018)

101 showed that an intense radiation in a frequency band 60-66 MHz abruptly started with the first 102 pulse and was present during the entire pulse train of both regular PB and isolated breakdown 103 processes. Ma (2017) used the term PB-type flashes for PB pulses not followed by negative CG 104 and found them to occur at the early stage of isolated thunderstorms. Zhang et al. (2002) reported 
the polarity-inverted IC discharges, which originated from the middle negative charge region and propagated downward to the lower positive charge region (LPCR), where they developed horizontally. Qie et al. (2008) found a majority of IC discharges to originate in the lower dipole during a major stage of a hailstorm at Tibetan Plateau. They called them lower level IC flashes and speculated that hails in the lower part of the cloud substantially contribute to the unusual strength of the LPCR. Zhang et al. (2015) hypothesized that the initiation processes of the inverted IC discharges, normal negative CG discharges and hybrid IC-CG discharges did not differ and that their later differentiation was controlled by the strength of the LPCR. Chilingarian et al. (2020) observed a termination of terrestrial gamma-ray enhancements by inverted IC discharges. This means that electric field between the main negative charge region and the LCPR was strong enough to accelerate electrons.

The role of LPCR in an evolution of discharges was also intensively modeled (Nag and Rakov, 2009; Tan et al., 2005; Iudin et al., 2017). Tan et al. (2014) found that the types and polarities of lightning discharges might depend on locations and magnitudes of oppositely charged layers near initiation points. For negative CG flashes, the magnitude of the LPCR near the lightning initiation needed to be strong enough for initiation breakdown, however an exceptionally strong LPCR could obstruct further propagation of the discharge down to the ground. Iudin et al. (2017) similarly concluded that a strong LPCR could block further vertical extension of the discharge.

This overview shows that lightning events characterized by PB pulses, which fail to evolve into negative stepped leaders and subsequent return strokes, were given different labels in the literature: "attempted CG leaders" (Nag and Rakov, 2008,2009), "isolated breakdown ” (Sharma et al, 2008; Esa et al., 2013a,b; Kolmasova et al., 2018), "inverted IC discharges" 
128 (Zhang et al., 2002, 2015; Nag and Rakov, (2009); Chilingarian et al., 2020), "low-level IC

129 flashes" (Qie et al., 2008), or "PB-type flashes” (Ma, 2017). All these expressions probably

130 describe the same phenomenon. Out of these possibilities, we think that "isolated breakdown" is

131 the best term to characterize what actually happens in the cloud, because properties of these

132 events are far from normal IC discharges, but close to the breakdown processes preceding

133 normal negative $\mathrm{CG}$ discharges.

In the present letter, we report results of our new investigation of properties of the

135 isolated breakdown processes including their pulse train characteristics and propagation

136 schemes. Our analysis is based on a combination of broadband magnetic-field measurements,

137 narrowband electric-field Lightning Mapping Array (LMA) records, and Low Frequency

138 detections of the French operational Météorage network. For the first time, we discuss this

139 phenomenon based on larger number of cases compared to previous studies dealing only with

140 several cases (Zhang et al. 2002; Coleman et al. 2008). Our analysis of more than 100 isolated

141 breakdown events allows us to draw new conclusions about their propagation schemes. The

142 observations were collected in Mediterranean during two observational campaigns in September

143 - November 2015 and September - November 2018 in the frame of the SOLID (Space-based

144 Optical LIghtning Detection) and the EXAEDRE (EXploiting new Atmospheric Electricity Data

145 for Research and the Environment) projects, respectively. Our results show that the duration of

146 isolated breakdown pulse trains, the inter-pulse intervals, and the regularity of their temporal

147 distribution in the analyzed events are similar to PB processes preceding regular CG discharges

148 but are very different from typical initial breakdown processes of normal IC discharges. We

149 present for the first time two typical scenarios of the isolated breakdown processes: (i) negative

150 leaders keep propagating horizontally for more than $150 \mathrm{~ms}$ (73\%) or (ii) discharges 
151 substantially weaken within the same time interval (27\%). In sections 2 and 3 we describe both

152 instrumental setup and dataset. In section 4, we present results of our analysis of the

153 measurements. In section 6, we discuss and summarize our results.

154

155

\section{Instrumentation}

To detect fluctuations of the E-W horizontal component of magnetic field we use the broadband analyzer BLESKA (Broadband Lightning Electromagnetic Signal Keeper Analyzer) (Kolmasova et al., 2018), a clone of the IME-HF analyzer (Instrument de Mesure du champ Electrique Haute Fréquence) developed for the TARANIS (Tool for the Analysis of Radiation from lightning and Sprites) spacecraft (Blanc et al., 2007) and adapted for ground-based measurements. The analyzer is connected to the magnetic sensor SLAVIA (Shielded Loop Antenna with a Versatile Integrated Amplifier) and detects signals in the frequency range from 5 $\mathrm{kHz}$ to $37 \mathrm{MHz}$, sampled at $80 \mathrm{MHz}$. The absolute time is obtained from a GPS receiver with an accuracy of $1 \mu \mathrm{s}$. The duration of triggered waveform snapshots is $208 \mathrm{~ms}$. The receiver was installed close to Ersa, France $\left(550 \mathrm{~m}, 42.97^{\circ} \mathrm{N}, 9.38^{\circ} \mathrm{E}\right)$, at the northernmost point of the Corsica island, in 2015. It was moved by a few kilometers in $2018\left(100 \mathrm{~m}, 43.00^{\circ} \mathrm{N}, 9.36^{\circ} \mathrm{E}\right)$. BLESKA detects broadband pulses exhibiting peak-to-peak amplitudes larger than $0.4 \mathrm{nT}$ which is well above the level of environmental interferences.

The magnetic field records are combined with the measurements of 12-LMA-station SAETTA (Suivi de l'Activité Electrique Tridimensionnelle Totale de l'Atmosphère) network 171 operated in Corsica since June 2014 (Rison et al., 1999; Coquillat et al., 2019). Each station is

172 equipped with an electric-field antenna and detects very high frequency (VHF) radiation emitted 173 by lightning discharges in the $60-66 \mathrm{MHz}$ band and sampled at $25 \mathrm{MHz}$. In each $80-\mu$ s time 174 interval, the individual stations identify the times of arrival of the strongest VHF peak exceeding 
175 a predefined threshold. The arrival times of the radiation peaks coming from the same source and 176 detected by at least six individual LMA stations are used to calculate the 3D-location of a VHF

177 radiation source. SAETTA also estimates power of individual geo-located VHF sources. GPS

178 receivers are connected to each LMA station and provide a time assignment with an accuracy of $1791 \mu \mathrm{s}$ (Thomas et al., 2004).

180 Locations, polarities, and peak currents for discharges used in our study were provided by 181 the French lightning locating system Météorage. To achieve an optimum coverage of the South182 East France and Corsica regions it combines sensors installed across France, and sensors 183 operated by Italian national service SIRF. The detection efficiency is $94 \%$, the median location 184 accuracy 120 meters (Pedeboy and Toullec, 2016) and the accuracy of estimation of peak current 185 amplitudes is about 18\% (Schulz et al., 2016). Characteristics of both CG and IC discharges were 186 available for both 2015 and 2018 datasets with an improved IC discharge detection efficiency for 1872018.

190 We visually inspected all triggered 208-ms long magnetic-field waveform captures recorded 191 by BLESKA during autumn 2015 and autumn 2018 in order to identify sequences of bipolar 192 pulses. We have chosen only the magnetic-field records containing pulse trains during which 193 SAETTA was able to geo-locate at least one VHF source. To distinguish isolated breakdown 194 events from usual PB pulses preceding -CG lightning and from PB preceding normal IC 195 discharges, we used the following criteria:

196 i) RS pulses were absent after the initial pulse sequence within the 208-ms long magnetic197 field waveform snapshots. 
198 ii) The list of Météorage records did not contain any CG detection within 1s after the time of the strongest isolated breakdown pulse in magnetic field records.

200

201

202

iii) Knowing that the usual PB pulses have the same initial polarity as the corresponding RS pulses (Rakov and Uman, 2003), we selected only trains of pulses that exhibited the same polarity as negative RS pulses. This criterion together with a visual inspection of the pulse train waveforms leads to the exclusion of PB pulse trains preceding normal polarity IC discharges. We were able to check the pulse polarity without any ambiguity by combining the magnetic loop antenna orientation with the locations of the IC pulses detected by Météorage. By applying this polarity criterion, we reduced our dataset by $20 \%$. We verified that the arrival azimuth of all analyzed events was further than 2 degrees from the eastward and westward directions (perpendicular to our magnetic loop) to avoid any misclassification of the polarity. A visual inspection of excluded trains showed that all excluded events lacked at least one typical signature of PB pulse trains preceding -CGs: i.e., duration of about 1-2 ms, inter-pulse intervals of about $100 \mu \mathrm{s}$, and a regular temporal distribution of pulses (Nag and Rakov, 2008). We also noted that the peak amplitude of pulses randomly varied within the trains for all excluded events.

The resulting dataset consists of 128 isolated breakdown events (33 events in 2015; 95 events in 2018).

\section{Data Analysis}

The sequences of the isolated breakdown pulses identified in the magnetic-field records were usually a few milliseconds long. They were preceded by an electromagnetically quiet period lasting several tens of milliseconds in all cases. The inter-pulse intervals lasted from several tens of microseconds to a few hundred of microseconds. The strongest pulses in 
222 individual sequences usually occur during the first millisecond after the first recognizable pulse.

223 The pulse activity following the sequences of the isolated breakdown pulses was weak or

224 completely absent. Two examples of magnetic-field waveforms containing the isolated

225 breakdown events recorded by BLESKA are shown in Figs. 1a and 2a, displaying a detail of 3

226 ms, while Figs. 1b, 1c, 2b, and 2c present the whole 208-ms long waveforms. Waveforms in Fig.

2271 and Fig. 2 were respectively captured on October 2, 2018 and October 13, 2015. Red arrows

228 point at the time of Météorage IC detections. Their peak currents were estimated to $16.2 \mathrm{kA}$ and

$2299.4 \mathrm{kA}$, respectively.

230 Correspondence of the isolated breakdown pulses measured by BLESKA and the VHF

231 sources geo-located by SAETTA is shown in Fig.1a, 1b, 2a, and 2b: each dot corresponds to one

232 reconstructed source of VHF radiation color-coded by its power. It is evident from Figs. 1a and

233 2a that almost none of the observed isolated breakdown pulses have a counterpart within the geo-

234 located VHF radiation sources during the displayed three milliseconds. This effect was already

235 reported by Kolmasova et al., 2018, and explained by a decreased ability of the LMA system to

236 geo-locate VHF sources if the counts of samples above the threshold reached a maximum of

2372000 (40-ns) detections within an 80- $\mu$ s LMA window at individual stations. This maximum of

2382000 detections was regularly reached at the LMA stations located close to developing

239 discharges suggesting that continuous VHF radiation was received during the initial phase of the

240 isolated breakdown events. During the 208 ms-long records in Figs. 1b and 2b, SAETTA was

241 able to geo-locate 444 and 159 VHF sources, respectively. The number of geo-locations during

242 all 128 events varies from 1 (our condition for including an event in the analysis) to 843 VHF

243 sources. The first geo-located VHF source occurred within the $\pm 1 \mathrm{~ms}$ window around the first

244 detectable isolated breakdown pulse in $75 \%$ of cases. In more than $85 \%$ of events, the geo- 
245 located VHF source occurring close to the first detectable magnetic-field pulse was also the most 246 powerful one, with power varying from 8 to $36 \mathrm{dBW}$ (24 dBW on average). Geo-located VHF

247 sources occurring later in time were weaker in amplitude, and, similarly as in Figs. 1b and 2b,

248 their power did not exceed $20 \mathrm{dBW}$. VHF sources were predominantly reconstructed at an

249 altitude between 2 and $6 \mathrm{~km}$, even if some sources appeared also below and above this altitude

250 range (for an overview, see animations S1 and S2 in the Supporting Information). We also noted

251 localized VHF sources, which did not have their counterparts in the broadband waveforms.

252 These VHF sources occurred especially in the later part of the records, well behind the train of

253 the isolated breakdown pulses. This effect can be explained by a lower sensitivity of the

254 broadband analyzer to signals generated by horizontal currents. We also speculate that during the

255 horizontal propagation of the discharges, the in-cloud channels might become shorter, and as a

256 result, the frequency of emitted radiation might have shifted above the upper frequency limit of

257 the broadband receiver (37 MHz) but still stay detectable by SAETTA at $66 \mathrm{MHz}$. Kolmasova et

258 al. (2018) reported that individual peaks of strong VHF radiation recorded at individual stations

259 (raw LMA data) still corresponded well to the broadband pulses during lightning initiation, even

260 in the situation when the LMA was unable to reconstruct geo-located VHF sources. Examples of

261 VHF radiation detected by SAETTA station B are illustrated in Figs. 1c (29 km away) and 2c

262 (108 km away). VHF radiation in Fig.1c remained very intense up to the end of the record, while

263 in Fig. 2c it was generally weaker and the counts and strengths of VHF sources dropped after

$264120 \mathrm{~ms}$ to very low values, suggesting a different discharge development. We inspected the time

265 evolution of both strength and count of raw LMA station data for the 128 events and found that

266 for three quarters of them the intense VHF radiation continued to occur at least for the closest

267 LMA station up to the end of the 208-ms long magnetic-field record, similarly to Fig. 1c. For the 
remaining quarterof cases, the VHF radiation substantially dropped at all LMA stations before the end of the magnetic-field record, similarly to Fig. 2c.

We illustrate the propagation of discharges starting with the isolated breakdown pulses in Figs. 1d-f and 2d-f. Each dot represents one geo-located VHF source color-coded by its time of occurrence. The discharge in Fig. 1 started at an altitude of about $2 \mathrm{~km}$, moved up by about two kilometers in $30 \mathrm{~ms}$, and kept propagating with nearly horizontal branches in a limited interval of altitudes for $100 \mathrm{~ms}$ (Fig. 1b). Finally, one branch moved down back to the initiation altitude and the other one propagated horizontally. This discharge was recorded during a weak lightning activity (7 discharges over $20 \mathrm{~min}$ ). It was the first discharge of a 3-discharge sequence of 150second duration with a similar vertical distribution of geo-located VHF sources. The discharge in Fig. 2 shortly propagated almost at a constant altitude (Fig. 2b). This discharge was also recorded during a rather weak lightning activity (7 discharges in 12 minutes). After combining all 3D propagation maps with the information about the presence/absence of VHF sources detected at individual LMA stations for all isolated breakdown events, we identify two different propagation scenarios: the discharges continue to propagate horizontally for more than $150 \mathrm{~ms}$ (Type A, as in Fig. $1-73 \%$ ), or they fade out sooner than 150ms (Type B, as in Fig. $2-27 \%$ ).

We inspected the magnetic field waveforms of individual pulse trains in order to compare their characteristics with typical signature of PB pulse trains prior -CGs: duration of about 1-2 ms, inter-pulse intervals of about $100 \mu \mathrm{s}$, and a regular distribution of bipolar pulses (Nag and Rakov, 2008). We have found that the majority of the pulse sequences lasted about two milliseconds or less for both scenarios (91\% of type A events:, $94 \%$ of type B events); the pulses within the trains were bipolar in all cases and regularly distributed in more than one half of cases (57\% of type A events, $66 \%$ of type B events). Inter-pulse intervals were typically about $100 \mu \mathrm{s}$ 
291 long (82\% of type A events, $60 \%$ of type B events). The intervals between pulses within

292 individual trains were sometimes also shorter, about $50 \mu$ s (9\% of type A events, $20 \%$ of type B

293 events) or longer up to $150-200 \mu$ s (9 \% of type A events, $20 \%$ of type A events).

294 In $86 \%$ of cases for both scenarios, the pulse peak amplitudes within the entire duration

295 of trains were monotonically increasing and then decreasing or only decreasing (examples in Fig.

296 3). In the remaining $14 \%$ of cases for both scenarios, the pulse peak amplitudes were distributed

297 randomly within the pulse sequences.

Fig. 3e shows that the two scenarios do not imply any clear differences in terms of spatial 299 distributions of the locations of the first geo-located VHF source in each event, time-stamped 300 close to the first recognizable isolated breakdown pulse. Fig. $3 f$ presents the distribution of peak 301 currents reported by Météorage, always corresponding to a pulse with the largest amplitude in 302 each individual sequence. Median values of the peak current are $20 \mathrm{kA}$ and $17 \mathrm{kA}$ for types A 303 and B, respectively. Note that these distributions are similar in both cases, and that the currents 304 might be underestimated for both categories, as shown by Kaspar et al. (2016). The distribution 305 of initiation heights for types A and B is again similar (Fig. 3g) with median values of $3.5 \mathrm{~km}$ 306 and $3.8 \mathrm{~km}$, respectively.

\section{Discussion and summary}

We have analyzed 128 sequences of the isolated breakdown pulses observed simultaneously

311 by a broadband receiver, a LMA network, and Météorage in West Mediterranean for two

312 periods, in 2015 and in 2018. We verified findings of Kolmasova et al. (2018) that intense VHF

313 radiation in raw LMA data coincides with the first isolated breakdown pulse in the broadband 314 magnetic-field measurements and that the most intense VHF radiation are often correlated with 
315 the broadband pulses. The number of geo-located VHF sources within the $208 \mathrm{~ms}-$ long

316 magnetic-field records, varied from units to hundreds. There were only a few geo-located VHF

317 sources occurring simultaneously with the magnetic-field isolated breakdown pulse trains. In the

318 majority of cases ( $85 \%$ ), the VHF sources occurring within $1 \mathrm{~ms}$ around the first detectable

319 isolated breakdown pulse in each event were also the most powerful ones detected during each

320 pulse train. Their power ranged from 8 to $36 \mathrm{dBW}$ ( $\sim 6 \mathrm{~W}$ to $4 \mathrm{~kW})$, about two orders of

321 magnitude weaker than the typical VHF power accompanying Narrow Bipolar Events as

322 reported by Bandara et al. (2020), but by two orders of magnitude stronger than the typical VHF

323 radiation detected around the initiation event of -CG flashes or normal IC discharges (Marshall et

324 al., 2019).

325 We have identified two scenarios of the isolated breakdown process based on the 128

326 sequences: the discharge continues to propagate horizontally for more than 150 ms (Type A - 73

$327 \%$ ) or dies out sooner (Type B - $27 \%$ ). Typical in-cloud currents, which generated the strongest

328 isolated breakdown pulses are similar for both types. These currents are reported by Météorage

329 around $20 \mathrm{kA}$ and they do not differ from peak currents, which emitted the most intense PB

330 pulses preceding -CG discharges in Florida, US (Karunarathne et al., 2019). Typical initiation

331 altitudes $(3.5 \mathrm{~km}$, similar for both types) correspond to the region between the main negative and

332 lower positive charge centers, where -CG discharges are initiated (Stolzenburg and Marshall,

333 2008). Geo-located VHF sources occurring close to the first detectable magnetic-field pulses in

334 both types of trains also exhibited similarly strong power (on average $24 \mathrm{dBW}$ ). Our analysis of

335 pulse train wave shapes shows that isolated breakdown pulse trains of both types cannot be

336 distinguished from the reported pulse sequences preceding -CG discharges (e.g., Kolmasova et

337 al., 2014, 2018, 2019; Zhang et al, 2015; Smith et al, 2018) and exhibit different properties 
compared to the ones of initiation pulses preceding normal IC discharges (Nag and Rakov, 2008;

339 Nag et al., 2009). These results therefore indicate that isolated breakdown processes of both types correspond to usual -CG discharges, which failed to propagate to ground. Several modeling investigations (Nag and Rakov et al., 2009; Tan et al., 2014; and Iudin et al., 2017) show that an excessive LPCR can play a crucial role in blocking the propagation of the $\mathrm{CG}$ discharges through

343 a potential well. Figs $1 \mathrm{~S}$ and $2 \mathrm{~S}$ in the Supporting Information show how this potential well 344 changes as a function of LPCR properties. Both a larger strength and/or a lower altitude of the 345 LPCR can lead to the development of a positive potential well below it. Our results are 346 consistent with the outcomes from Iudin et al. (2017) even though they used a different LPCR 347 charge distribution, position, radius, and thickness. Our results also agree with observation from 348 Coleman et al. (2008) who combined balloon measurements of vertical electric field and LMA 349 VHF sources and found that horizontal extensions of lightning channels correlated with 350 potential extrema.

351 In conclusion, we find that the isolated breakdown events (also known as attempted -CG 352 leaders, inverted IC discharges, low-level IC flashes, or PB-type flashes) can show two different 353 discharge propagation scenarios: the discharge either continues to propagate horizontally or 354 quickly fades out. Based on the observed duration of the isolated breakdown pulse trains, on the 355 inter-pulse intervals, on their regularity, and on the bipolar shapes of the pulses, as well as on the 356 geo-localization of their sources, we find that both scenarios described in this study are similar to 357 PB processes preceding -CG flashes. More studies are needed to detail the geographical or 358 seasonal variation of these two types of the isolated breakdown processes and their relation to the 359 microphysical and electrical structure of the parent thunderstorms.

\section{Acknowledgements}


362 The work of IK and OS was supported by European Regional Development Fund-Project

363 CRREAT (CZ.02.1.01/0.0/0.0/15_003/0000481) and by the Praemium Academiae award of the

364 Czech Academy of Sciences. The work of PK, AK, RL and LU was supported by the GACR

365 grant 20-09671S. The work from ED, SC and SP was supported by CNES through the SOLID

366 project and by ANR through the ANR-16-CE04-0005 EXAEDRE project. The SAETTA

367 network was operated with the support from CNES, HyMeX program, and Collectivité de Corse.

368 The broadband data are available at http://bleska.ufa.cas.cz/ersa/storage/tar/. The SAETTA data

369 are available at http://babeta.ufa.cas.cz/repository/data_2020GL090593.html. 


\section{References}

Bandara, S., T. Marshall, S. Karunarathne, \& M. Stolzenburg (2020), Electric field change and VHF waveforms of Positive Narrow Bipolar Events in Mississippi thunderstorms, Atmos. Res.243, doi:org/10.1016/j.atmosres.2020.105000.

Bazelyan, E. M., \& Y. P. Raizer (2000), Lightning physics and lightning protection. CRC Press.

Blanc, E., F. Lefeuvre, R. Roussel-Dupré, \& J. Sauvaud (2007), TARANIS: A microsatellite project dedicated to the study of impulsive transfers of energy between the Earth atmosphere, the ionosphere, and the magnetosphere, Adv. Space Res., 40(8), 1268-1275, doi:10.1016/j.asr.2007.06.037.

Chilingarian, A., Khanikyants, Y., Rakov, V. A., \& Soghomonyan, S. (2020). Termination of thunderstorm-related bursts of energetic radiation and particles by inverted intracloud and hybrid lightning discharges. Atmospheric Research, 233, 104713

Coleman, L. M., M. Stolzenburg, T. C. Marshall, \& M. Stanley (2008), Horizontal lightning propagation, preliminary breakdown, and electric potential in New Mexico thunderstorms. J. of Geophys. Res.: Atm., 113(D9), doi: 10.1029/2007JD009459.

Coquillat, S., Defer, E., de Guibert, P., Lambert, D., Pinty, J.-P., Pont, V., Prieur, S., Thomas, R. J., Krehbiel, P. R., and Rison, W.: SAETTA: high-resolution 3-D mapping of the total lightning activity in the Mediterranean Basin over Corsica, with a focus on a mesoscale convective system event, Atmos. Meas. Tech., 12, 5765-5790, https://doi.org/10.5194/amt-12-5765-2019, 2019.

Iudin, D. I., V. A. Rakov, E. A. Mareev, F. D. Iudin, A. A. Syssoev, \& S. S. Davydenko (2017), Advanced numerical model of lightning development: Application to studying the role of LPCR in determining lightning type, J. Geophys. Res. Atmos., 122, 6416-6430, doi:10.1002/2016JD026261. 
414 Kašpar, P., O. Santolík, I. Kolmašová, \& T. Farges (2016), A model of preliminary breakdown

415

416

417

418

419

420

421

422

423

424

425

426

427

428

429

430

431

432

433

434 pulse peak currents and their relation to the observed electric field pulses, Geophys. Res. Lett., 43, doi:10.1002/2016GL071483.

Kolmašová, I., O. Santolík, T. Farges, W. Rison, R. Lán, \& L. Uhlíŕr (2014), Properties of the unusually short pulse sequences occurring prior to the first strokes of negative cloud-toground lightning flashes, Geophys. Res. Lett., 41, 5316-5324, doi:10.1002/2014GL060913.

Kolmašová, I., O. Santolík, T. Farges, S. A. Cummer, R. Lán, and L. Uhlíř (2016), Subionospheric propagation and peak currents of preliminary breakdown pulses before negative cloud-to-ground lightning discharges, Geophys. Res. Lett., 43, 1382-1391, doi:10.1002/2015GL067364.

Kolmašová, I., O. Santolík, E. Defer, W. Rison, S. Coquillat, S. Pedeboy, et al. (2018), Lightning initiation: Strong VHF radiation sources accompanying preliminary breakdown pulses during lightning initiation, Scientific Reports, volume 8, Article number: 3650, doi:10.1038/s41598-018-21972-Z.

Kotovsky, D. A., R. C. Moore, Y. Zhu, M. D. Tran, V. A. Rakov, J. T. Pilkey, et al. (2016), Initial breakdown and fast leaders in lightning discharges producing long-lasting disturbances of the lower ionosphere, J. Geophys.Res. Space Physics, 121, 5794-5804, doi:10.1002/2015JA022266.

Ma, D. (2017), Characteristic pulse trains of preliminary breakdown in four isolated small thunderstorms, J. Geophys. Res. Atmos., 122, 3361-3373, doi:10.1002/2016JD025899. 
Mansell, E. R., D. R. MacGorman, C. L. Ziegler, \& J. M. Straka (2002), Simulated threedimensional branched lightning in a numerical thunderstorm model, J. Geophys. Res. Atmos., 107(D9), doi: 10.1029/2000JD000244.

Marshall, T., W. Schulz, N. Karunarathna, S. Karunarathne, M. Stolzenburg, C. Vergeiner, \& T. Warner (2014a), On the percentage of lightning flashes that begin with initial breakdown pulses, J. Geophys. Res. Atmos., 119, 445-460, doi:10.1002/2013JD020854.

Marshall, T., M. Stolzenburg, N. Karunarathna, \& S. Karunarathne (2014b), Electromagnetic activity before initial breakdown pulses of lightning, J. Geophys. Res. Atmos., 119, 12,558-12,574, doi:10.1002/2014JD022155.

Marshall, T., S. Bandara, N. Karunarathne, S. Karunarathne, I. Kolmasova, R. Siedlecki, \& M. Stolzenburg (2019), A study of lightning flash initiation prior to the first initial breakdown pulse, Atmospheric Research 217,10-23, doi:10.1016/j.atmosres.2018.10.013.

Mazur, V. \& L. H. Ruhnke (1998), Model of electric charges in thunderstorms and associated lightning. J. Geophys. Res. Atmos., 103(D18), 23299-23308, doi:0.1029/98JD02120.

Nag, A. \& V. A. Rakov (2008), Pulse trains that are characteristic of preliminary breakdown in cloud-to-ground lightning but are not followed by return stroke pulses, J. Geophys. Res. 113, D01102.

Nag, A., \& V. A. Rakov (2009), Some inferences on the role of lower positive charge region in facilitating different types of lightning. Geophysical Research Letters, $36(5)$.

Nag, A., B. A. DeCarlo, \& V. A. Rakov (2009), Analysis of microsecond- and submicrosecondscale electric field pulses produced by cloud and ground lightning discharges, Atmospheric Research 91, 316-325, doi:10.1016/j.atmosres.2008.01.014. 
Pedeboy, S. \& M. Toullec (2016), Impact study of the 'Millau Bridge' on the local lightning occurrence. in International Lightning Protection Symposium 2016.

Press, W. H., S. A. Teukolsky, W. T. Vetterling, \& B. P. Flannery (1996), Numerical recipes in $C$, volume 2. Citeseer.

Rakov, V. A., \& M. A. Uman (2003), Lightning - Physics and effects, Cambridge University Press, ISBN:9780521583275.

Rison, W., R.J. Thomas, P.R. Krehbiel, T. Hamlin, \& J. Harlin (1999), A GPS-based ThreeDimensional Lightning Mapping System: Initial Observations in Central New Mexico, Geophys. Res. Lett., 26, No. 23, 3573-3576.

Smith, E. M., Marshall, T. C., Karunarathne, S., Siedlecki, R., \& Stolzenburg, M. (2018). Initial breakdown pulse parameters in intracloud and cloud-to-ground lightning flashes. J. Geophys. Res. Atmos. 123, 2129-2140, doi:10.1002/2017JD027729.

Schulz, W., G. Diendorfer, S. Pedeboy, \& D. Roel Poelman (2016), The European lightning location system EUCLID - Part 1: Performance analysis and validation. Nat. Hazards Earth Syst. Sci. 16, 595-605.

Sharma, S.R., V. Cooray, \& M. Fernando (2008), Isolated breakdown activity in Swedish lightning, J. Atmos. Sol.-Terr. Phys. 70, 1213-1221, doi:10.1016/j.jastp.2008.03.003.

Stolzenburg, M. \& T. C. Marshall (2008), Charge structure and dynamics in thunderstorms. Space Science Reviews, 137, 355-372, doi:10.1007/s11214-008-9338-z.

Tan, Y., S. Tao, \& B. Zhu (2006), Fine-resolution simulation of the channel structures and propagation features of intracloud lightning. Geophys. Res. Lett, 33(9), doi:10.1029/2005GL025523. 
480 Tan, Y., S. Tao, Z. Liang, and B. Zhu (2014), Numerical study on relationship between lightning

481

482

483

484

485

486

487

488

489

490

491

492

493

494 Fig. 1 types and distribution of space charge and electric potential, J. Geophys. Res. Atmos., 109, 1003-1014, doi:10.1002/2013JD019983.

Thomas, R. J., P. R. Krehbiel, W. Rison, S. J. Hunyady, W. P. Winn, T. Hamlin, \& J. Harlin (2004), Accuracy of the Lightning Mapping Array, J. Geophys. Res., 109, D14207, doi:10.1029/2004JD004549.

Zhang, Y., Zhang, Y., Zheng, D., \& Lu, W. (2015). Preliminary breakdown, following lightning discharge processes and lower positive charge region. Atmospheric Research, 161, 52-56.

Zhang, Y., Krehbiel, P. R., \& Liu, X. (2002). Polarity inverted intracloud discharges and electric charge structure of thunderstorm. Chinese Science Bulletin, 47(20), 1725-1729 

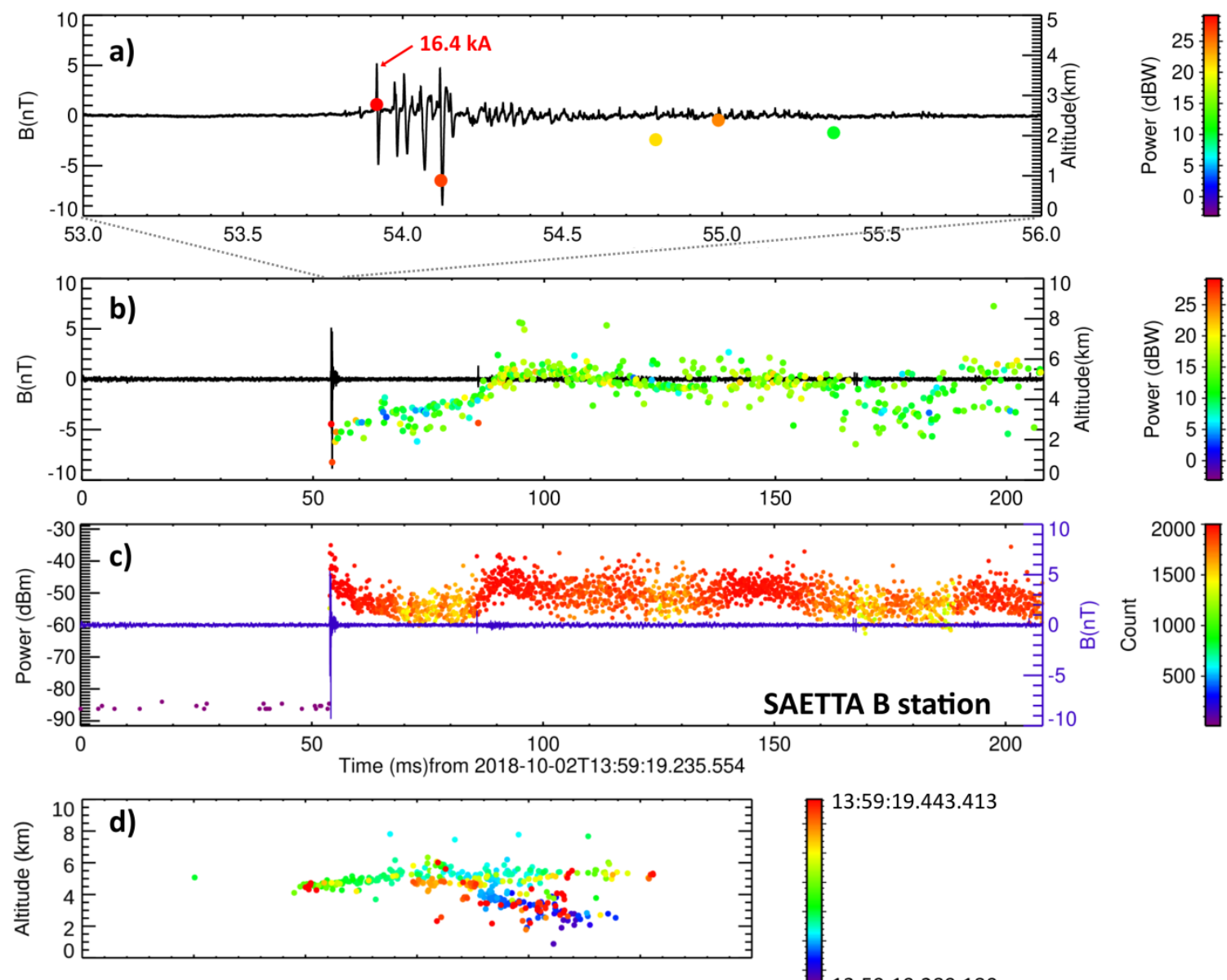

13:59:19.443.413

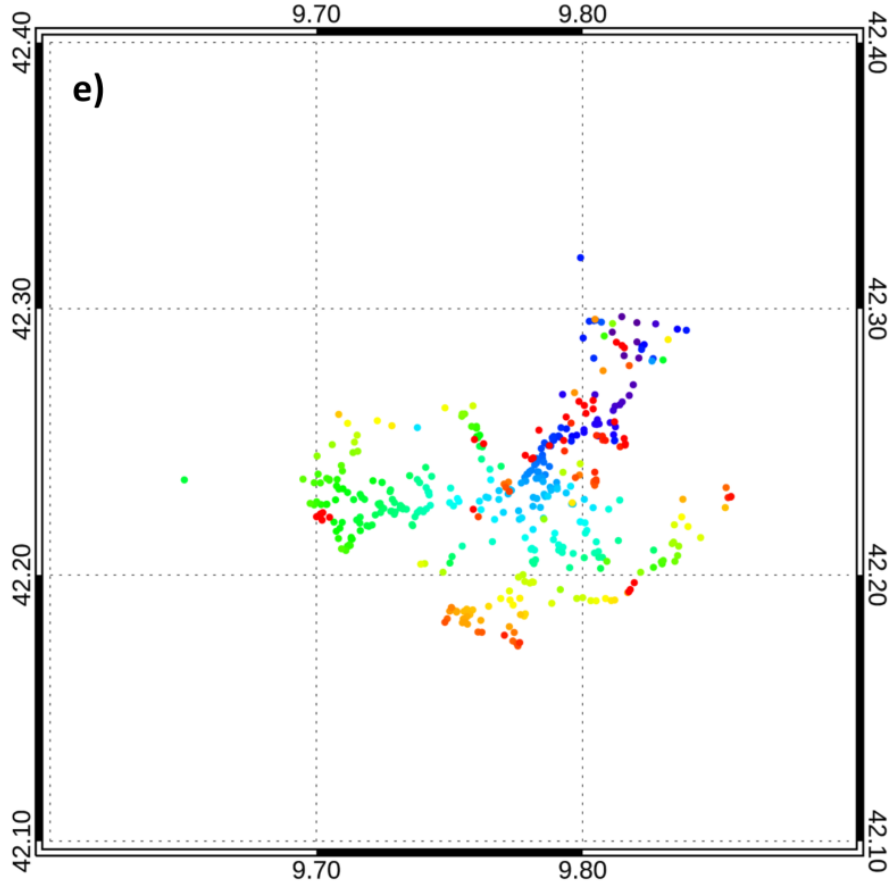

13:59:19.289.180

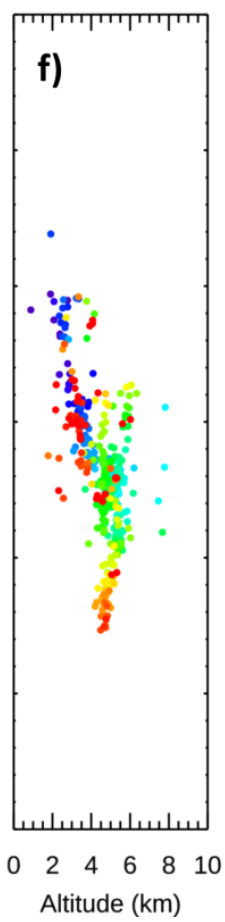


496 Fig.1 Example of an isolated breakdown event (type A) occurring on 2 Oct 2018 at 13:55:19.236

497 UT: (a) 3-ms long detail of the BLESKA waveform showing a sequence of isolated breakdown 498 pulses overlaid on altitude of geo-located SAETTA VHF radiation sources color-coded by their 499 power; (b) the whole 208 ms-long BLESKA record with geo-located VHF radiation sources; (c) 500 the BLESKA record with peaks of radiated VHF power recorded at the SAETTA station B

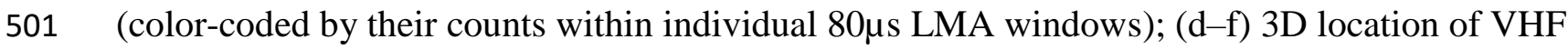
502 radiation sources color-coded by time (7 SAETTA stations minimum, $\chi^{2}<1$ ).

503

504

505

506

507

508

509

510

511

512

513

514

515

516

517

518

519

520

521

522

523

524

525

526
Fig. 2 Same as Fig. 1 but for an isolated breakdown event (type B) occurring on 13 Oct 2015 at 22:09:30.073 UT. 

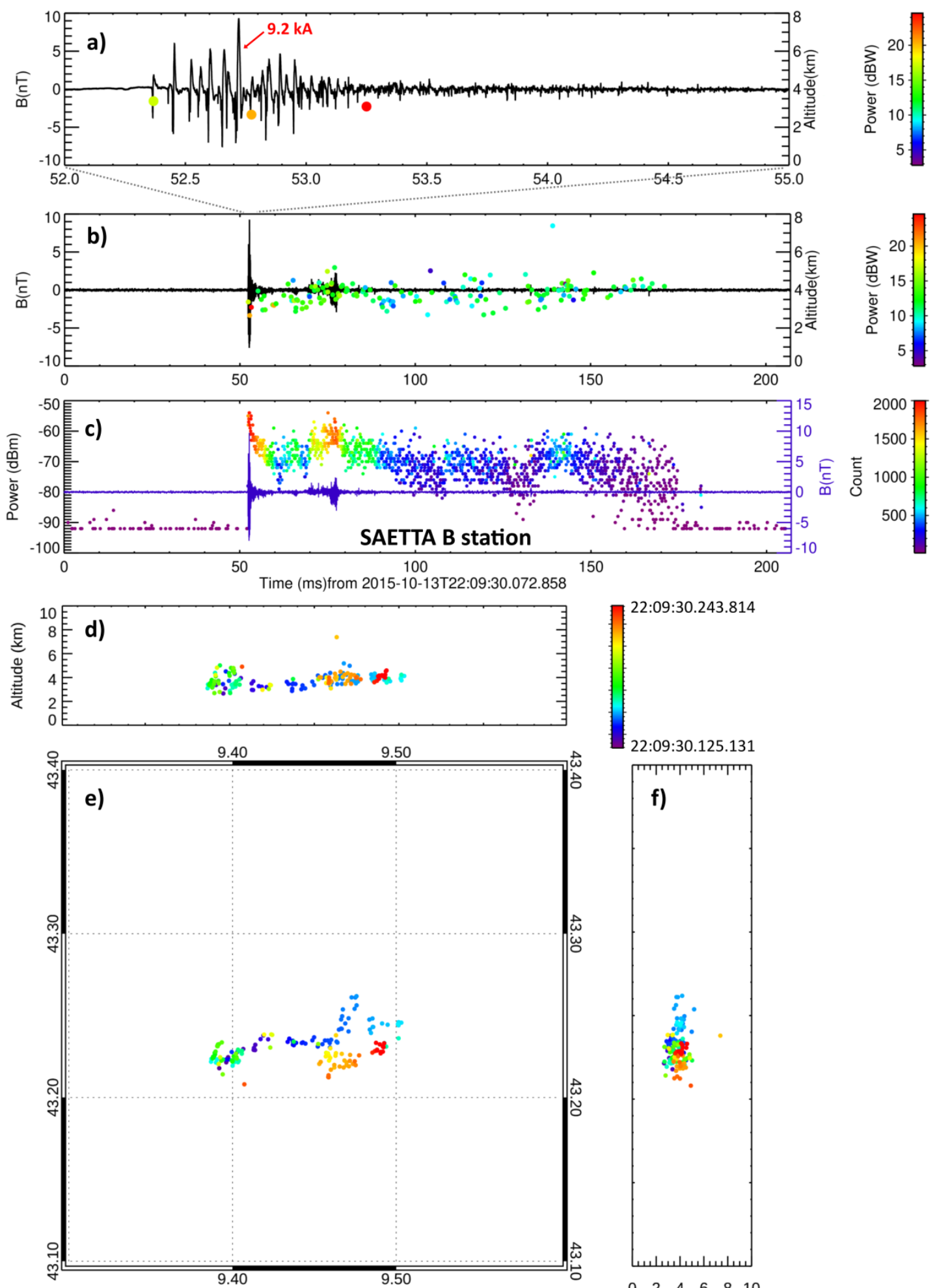

22:09:30.125.131

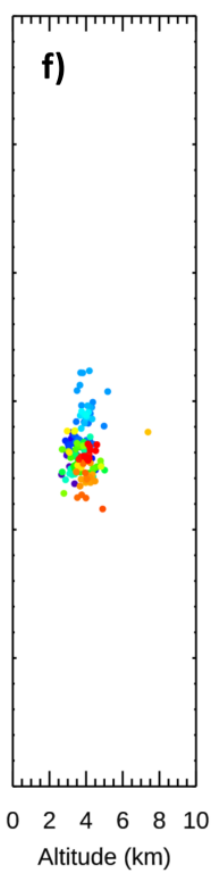

529 Fig. 3 

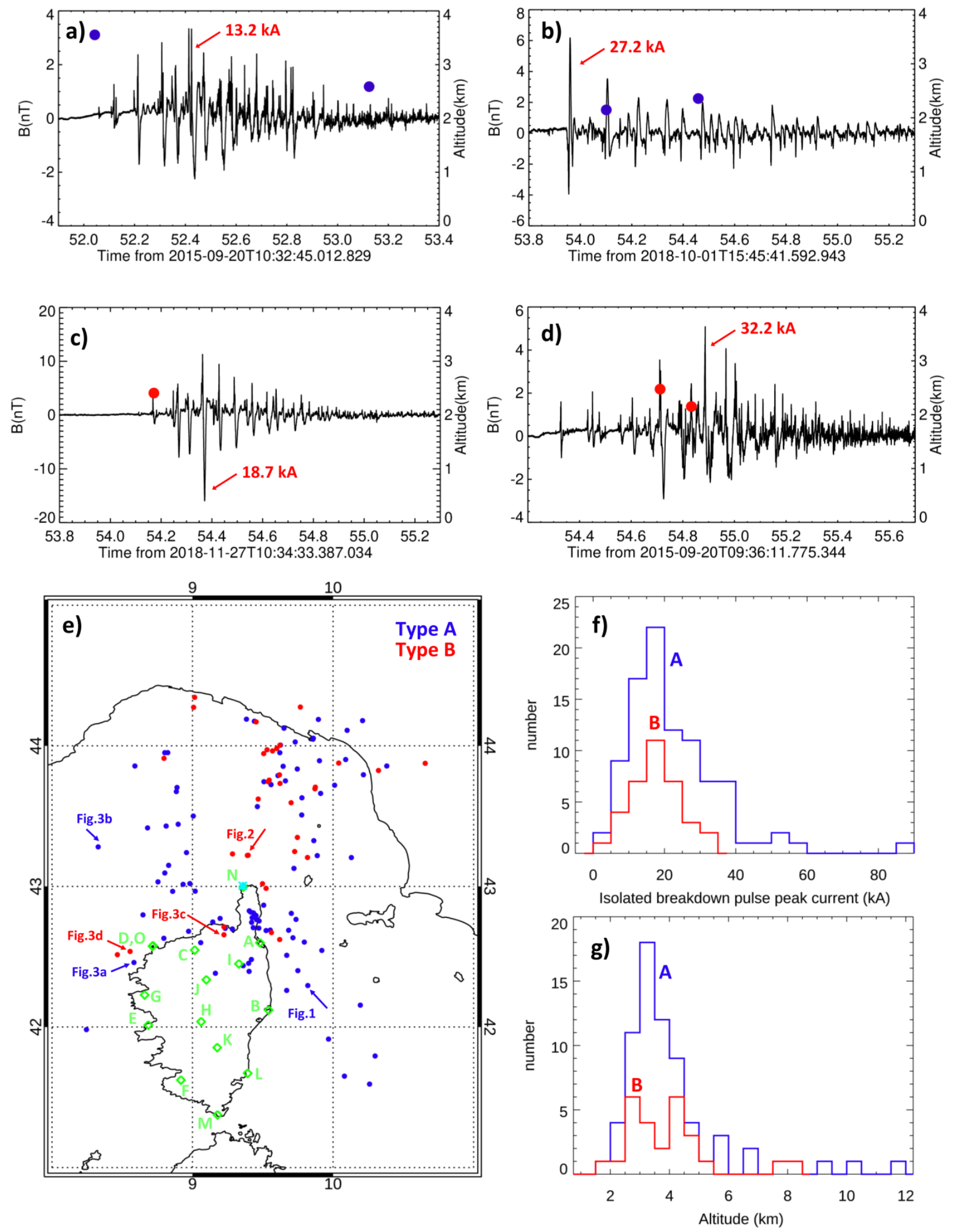
532 Fig.3 a-d) 1.5-ms long details of the BLESKA waveform showing sequences of isolated

533 breakdown pulses overlaid on altitude of geo-located SAETTA VHF radiation sources: (a)

534 isolated breakdown event (type A) occurring on 20 Sep 2015 at 10:32:45.013 UT, (b) isolated

535 breakdown event (type A) occurring on 01 Oct 2018 at 15:45:41.593 UT, (c) isolated breakdown

536 event (type B) occurring on 27 Nov 2018 at 10:34:33.387, (d) isolated breakdown event (type B)

537 occurring on 20 Sep 2015 at 09:36:11.775 UT, (e) Map showing the 2D location of the geo-

538 located VHF sources occurring within $1 \mathrm{~ms}$ from the first recognizable magnetic-field pulse

539 (blue: type A, red: type B). Green diamonds show the locations of SAETTA stations. The light

540 blue star locates the BLESKA receiver. The blue and red arrows point to the events shown in

541 Figs. 1, 2, and 3a-d, respectively. (f) Histograms of the Météorage peak current corresponding to

542 largest pulses identified within magnetic-field pulse sequences; (g) Histograms of initiation

543 heights obtained as altitudes of the LMA geo-located sources occurring within 1ms from the first

544 recognizable isolated breakdown pulse (altitude uncertainty: 20 m above Corsica and up $\sim 500$

$545 \mathrm{~m}$ at $200 \mathrm{~km}$ from the coast).

546

547

548

549

550

551

552

553

554

555

556 